\title{
Maximal Generalization of Pure Ideals
}

\section{Raida D. Mahmood}

raida.1961@uomosul.edu.iq

College of Computer science

and Mathematics

University of Mosul

Received on: 06/04/2006
Awreng B. Mahmood

awring2002@yahoo.com

College of Computer science and Mathematics

University of Mosul

Accepted on: 25/06/2006

\section{ABSTRACT}

The purpose of this paper is to study the class of the rings for which every maximal right ideal is left GP-ideal. Such rings are called MGP-rings and give some of their basic properties as well as the relation between MGP-rings, strongly regular ring, weakly regular ring and kasch ring.

Keywords: pure ideals, strongly regular, kasch ring .

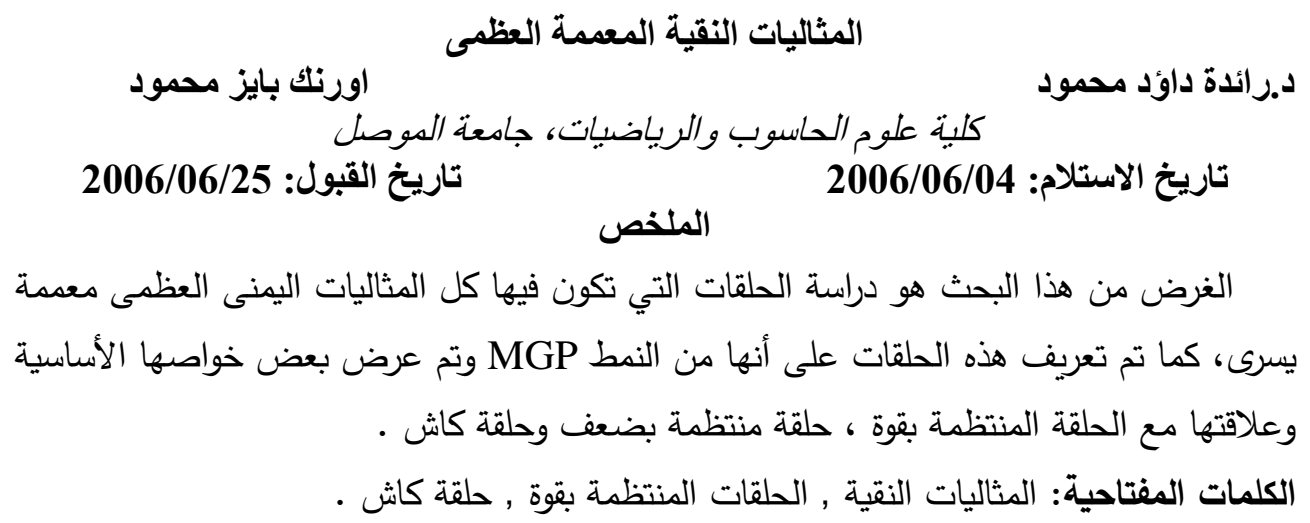

\section{1- Introduction :}

Throughout this paper, $\mathrm{R}$ denotes as associative ring with identity. An ideal $I$ of a ring $R$ is said to be right(left) pure if for every $a \in I$, there exists $\mathrm{b} \in \mathrm{I}$ such that $\mathrm{a}=\mathrm{ab}(\mathrm{a}=\mathrm{ba})$. This concept was introduced by Fieldhouse [6], [ 7 ], Al-Ezeh [ 2 ],[ 3 ] and Mahmood [ 9 ].

Recall that:-

1- A ring $R$ is regular if for every $a \in R$ there exists $b \in R$ such that $a=a b a$, if $a=a^{2} b, R$ is called strongly regular.

2-A ring without non-zero nilpotent elements is called reduced.

3-For any element $\mathrm{a} \in \mathrm{R}, \mathrm{r}(\mathrm{a})$ and $\mathrm{l}(\mathrm{a})$ denote the right annihilator and the left annihilator of a, respectively.

4- $\mathrm{A}$ ring $\mathrm{R}$ is said to be a left(right) uniform ring if and only if every nonzero left(right) ideals is essential .

5-Following [10], a ring $\mathrm{R}$ is said to be semi commutative if $\mathrm{xy}=0$ implies that $x \mathrm{R} y=0, x, y \in R$. Clearly every reduced ring is semi commutative. It 
is easy to see that $\mathrm{R}$ is semi commutative if and only if every left(right) annihilator in $\mathrm{R}$ is a two-sided ideal.

$6-\mathrm{Y}(\mathrm{R}), \mathrm{J}(\mathrm{R})$ are respectively the right singular ideal and the Jacobson radical of $R$.

\section{2- MGP-rings}

In this section, the concept of maximal GP-ideals is introduced and we use it to define MGP-rings .We study such rings and give some of their basic properties.

Following [8], an ideal I of a ring $\mathrm{R}$ is said to be right (left) GP-ideal (generalized pure ideal), if for every $\mathrm{a}$ in $\mathrm{I}$, there exists $\mathrm{b}$ in $\mathrm{I}$ and a positive integer $n$ such that $a^{n}=a^{n} b\left(a^{n}=b a^{n}\right)$.

\section{Definition 2.1 :}

A ring $\mathrm{R}$ is called a right (left) MGP-ring if and only if every maximal right (left) ideal is left (right) GP-ideal.

\section{Example:}

Let $\mathrm{Z}_{12}$ be the ring of the integers module 12 .

Then the maximal ideals, $\mathrm{I}=\{0,3,6,9\}, \mathrm{J}=\{0,2,4,6,8,10\}$ are GP-ideals.

The following theorem gives some interesting characteristic properties of right MGP-rings. Before that we need the next lemma in our proof.

\section{Lemma 2.2:}

Let $\mathrm{a}$ be a non zero element of a ring $\mathrm{R}$ and let $1(\mathrm{a})=0$. Then for every positive integer $n, 1\left(a^{n}\right)=0$.

Proof: obvious \#

\section{Theorem 2.3 :}

If $\mathrm{R}$ is a right MGP-ring and every ideal is principal, then any left regular element is right invertible .

\section{Proof :}

Let $0 \neq c \in R$, such that $1(c)=0$. If $c R \neq R$, then there exists a maximal right ideal $\mathrm{M}$ containing $\mathrm{cR}$. Since $\mathrm{R}$ is right MGP-ring, then $\mathrm{M}$ is a left GP-ideal, there exists $d \in M$ and a positive integer $n$, such that $c^{\mathrm{n}}=\mathrm{dc}^{\mathrm{n}}$ and $\mathrm{d}=\mathrm{cx}$, for some $\mathrm{x} \in \mathrm{R}$.

So ( 1-cx $) \in 1\left(c^{n}\right)$,Since $1(c)=0$, then by Lemma (2.2) we have $1\left(c^{n}\right)=0$, thus $c x=1 \in M$, this contradicts $c R \neq R$. Therefore $\mathrm{cR}=\mathrm{R}$, and hence $\mathrm{c}$ is a right invertible. \#

\section{Lemma 2.4 :}


Let $R$ be a reduced ring. Then for every $a \in R$, and every positive integer $\mathrm{n}, \mathrm{a}^{\mathrm{n}} \mathrm{R} \cap \mathrm{r}\left(\mathrm{a}^{\mathrm{n}}\right)=0$.

Proof: See [8]

\section{Proposition 2.5 :}

Let $\mathrm{R}$ be a reduced, MGP-ring. Then for every $\mathrm{a}$ in $\mathrm{R}$ and a positive integer $n, r\left(a^{n}\right)$ is a direct summand of $R$.

\section{Proof :}

To prove $r\left(a^{n}\right)$ is a direct summand, we claim that $a^{n} R+r\left(a^{n}\right)=R$. If this is not true, let $M$ be a maximal right ideal containing $a^{n} R+r\left(a^{n}\right)$. Since $\mathrm{R}$ is MGP-ring, so $\left(\mathrm{a}^{\mathrm{n}}\right)^{\mathrm{m}}=\mathrm{b}\left(\mathrm{a}^{\mathrm{n}}\right)^{\mathrm{m}}$ for some $\mathrm{b} \in \mathrm{M}$ and a positive integer $\mathrm{m}$, this implies $(1-b) \in 1\left(a^{\mathrm{nm}}\right)=\mathrm{r}\left(\mathrm{a}^{\mathrm{n}}\right) \subseteq \mathrm{M}$ ( $\mathrm{R}$ is reduced $)$, and so $1 \in \mathrm{M}$, a contradiction. Hence $\mathrm{a}^{\mathrm{n}} \mathrm{R}+\mathrm{r}\left(\mathrm{a}^{\mathrm{n}}\right)=\mathrm{R}$.

Now, since $a^{n} R \cap r\left(a^{n}\right)=0$,Lemma( 2.4), then $r\left(a^{n}\right)$ is a direct summand. \#

Recall that, a ring $\mathrm{R}$ is called a right (left) MP-ring if every maximal right (left) ideal is a left (right) pure.

We consider the condition $(*)$ : $\mathrm{R}$ satisfies $\mathrm{l}\left(\mathrm{b}^{\mathrm{n}}\right) \subseteq \mathrm{r}(\mathrm{b})$ for any $\mathrm{b} \in \mathrm{R}$ and a positive integer $\mathrm{n}$.

\section{Theorem 2.6 :}

Let $\mathrm{R}$ be a ring satisfying (*). Then $\mathrm{R}$ is a right MGP-ring if and only if $\mathrm{R}$ is strongly regular .

Proof:

If this is not true let $\mathrm{R}$ be a right MGP-ring and let $\mathrm{b}$ be any element in $\mathrm{R}$. We shall prove that $\mathrm{bR}+\mathrm{r}(\mathrm{b})=\mathrm{R}$.

If this is not true let $M$ be a maximal right ideal containing $b R+r(b)$. Since $\mathrm{R}$ is an MGP-ring, then there exists $\mathrm{a} \in \mathrm{M}$ and a positive integer $\mathrm{n}$ such that $\mathrm{b}^{\mathrm{n}}=\mathrm{ab}^{\mathrm{n}}$ which implies that $(1-\mathrm{a}) \in \mathrm{l}\left(\mathrm{b}^{\mathrm{n}}\right) \subseteq \mathrm{r}(\mathrm{b}) \mathrm{M}$, thus $\subset$

$1 \in \mathrm{M}$, a contradiction . Therefore $b R+r(b)=R$.

In particular, $\mathrm{bu}+\mathrm{v}=1$, for some $\mathrm{u} \in \mathrm{R}, \mathrm{v} \in \mathrm{r}(\mathrm{b})$.

So $b=b^{2} u$, therefore $R$ is strongly regular.

Conversely; assume that $\mathrm{R}$ is strongly regular, then by [1], $\mathrm{R}$ is regular and reduced. Also by [9] , $\mathrm{R}$ is an MP-ring and semi commutative, then $\mathrm{R}$ is an MGP -ring .\#

\section{Proposition 2.7 :}

Proof:

Let $\mathrm{R}$ be a right MGP-ring satisfying $(*)$. Then $\mathrm{Y}(\mathrm{R})=0$. 
If $Y(R) \neq 0$, then by a Lemma (7) of [10]; there exists $0 \neq a \in \mathrm{Y}(\mathrm{R})$ with $\mathrm{a}^{2}=0$.From Theorem (2.6) $\mathrm{R}$ is strongly regular, that is $a=a^{2} b$, for some $b \in R$. Hence $a=0$, contradiction. Therefore $Y(R)=$ 0. \#

\section{Proposition 2.8 :}

If $\mathrm{R}$ is a right MGP - ring, then any reduced principal right ideal of $\mathrm{R}$ is a direct summand .

Proof: Let $\mathrm{I}=\mathrm{aR}$ be a reduced principal right ideal of $\mathrm{R}$.If $\mathrm{aR}+\mathrm{r}(\mathrm{a} \neq) \mathrm{R}$, then there exists a maximal right ideal $M$ of $R$ containing $a R+r(a)$.

Now, since $R$ is a right MGP-ring and $a \in M$, then there exists $\mathrm{b} \in \mathrm{M}$ and a positive integer $\mathrm{n}$ such that $\mathrm{a}^{\mathrm{n}}=\mathrm{b} \mathrm{a}^{\mathrm{n}}$, and hence $(1-\mathrm{b}) \mathrm{a}^{\mathrm{n}}=0$. Since $\mathrm{I}$ is reduced then we have $(1-b) \in 1\left(\mathrm{a}^{\mathrm{n}}\right)=\mathrm{r}\left(\mathrm{a}^{\mathrm{n}}\right)=\mathrm{r}(\mathrm{a}) \subset \mathrm{M}$, this implies that $1 \in \mathrm{M}$, which contradicts $\mathrm{M} \neq \mathrm{R}$. Therefore, $\mathrm{aR}+\mathrm{r}(\mathrm{a})=\mathrm{R}$, thus $a=a^{2} c$ for some $c \in R$. If we set $d=a^{2} \in I$, then $a=a^{2} d$. implies that $\mathrm{a}=\mathrm{ada}$ and hence $\mathrm{aR}=\mathrm{e} \mathrm{R}$, where $\mathrm{e}=\mathrm{ad}$ is an idempotent element . Then by [6], aR is a direct summand. \#

\section{Proposition 2.9 :}

Let $\mathrm{R}$ be a right MGP-ring satisfying (*). If $\mathrm{a}^{\mathrm{n}} \mathrm{b}=0$, for any $a, b \in R$ and a positive integer $n$, then $r\left(a^{n}\right)+r(b)=R$.

Proof: Assume that $r\left(a^{n}\right)+r(b) R$. Let $M$ be a maximal right ideal $\neq$ containing $r\left(a^{n}\right)+r(b)$. Since $R$ is a right MGP-ring and $a^{n} b=0$ implies that $\mathrm{b} \in \mathrm{r}\left(\mathrm{a}^{\mathrm{n}}\right) \subseteq \mathrm{M}$, there exists $\mathrm{c} \in \mathrm{M}$ and a positive integer $\mathrm{m}$ such that $\mathrm{b}^{\mathrm{m}}=\mathrm{cb}^{\mathrm{m}}$, so( $\left.1-\mathrm{c}\right) \in \mathrm{l}\left(\mathrm{b}^{\mathrm{m}}\right) \subseteq \mathrm{r}(\mathrm{b}) \subset \mathrm{M}$, which implies that $1 \in \mathrm{M}$, which is a contradiction . Therefore $r\left(a^{n}\right)+r(b)=R$.

\section{Theorem 2.10 :}

Let $\mathrm{R}$ be a uniform semi commutative, MGP-ring and every ideal is principal. Then $\mathrm{R}$ is a division ring .

Proof : Let $0 \neq \mathrm{a} \in \mathrm{R}$ and $\mathrm{aR} \neq \mathrm{R}$, and let $\mathrm{M}$ be a maximal right ideal containing $\mathrm{aR}$. Since $\mathrm{R}$ is an MGP-ring, then there exists $\mathrm{b} \in \mathrm{aR} \subseteq \mathrm{M}$, and a positive integer $n$ such that $a^{n}=b a^{n}$.

This implies that $\mathrm{a}^{\mathrm{n}}=\mathrm{aca}^{\mathrm{n}}$, for some $\mathrm{c} \in \mathrm{R}$. Since $\mathrm{R}$ is uniform so every ideal is an essential ideal.

Let $\mathrm{x} \in \mathrm{r}\left(\right.$ ar) $\cap \mathrm{a}^{\mathrm{n}} \mathrm{R}$. Then acx $=0$ and $\mathrm{x}=\mathrm{a}^{\mathrm{n}} \mathrm{z}$ for some $\mathrm{z} \in \mathrm{R}$, so $\mathrm{aca}^{\mathrm{n}} \mathrm{z}=0$, yields $\mathrm{a}^{\mathrm{n}} \mathrm{z}=0=\mathrm{x}$. Therefore, $\mathrm{r}(\mathrm{ac}) \cap \mathrm{a}^{\mathrm{n}} \mathrm{R}=0$, since $\mathrm{R}$ is a uniform ring and $a^{n} R \neq 0$, then $r(a c)=0$. Since $R$ is semi commutative , $1(\mathrm{ac})=0$, then by Theorem (2.3) ac is a right invertible element ,so there 
exists $\mathrm{v} \in \mathrm{R}$ such that $\mathrm{acv}=1$. Hence $\mathrm{a}(\mathrm{cv})=1 \in \mathrm{M}$, which is a contradiction. Therefore $\mathrm{aR}=\mathrm{R}$.

Now, since $\operatorname{ar}=1 \quad(\mathrm{aR}=\mathrm{R})$,we have ara=a which implies that $(1-r a) \in \mathrm{r}(\mathrm{a})=\mathrm{l}(\mathrm{a}) \subseteq \mathrm{l}(\mathrm{ar})=\mathrm{r}(\mathrm{ar})=0$.Therefore, $(1-\mathrm{ra})=0$, whence $\mathrm{ra}=1$,so a is a left invertible .Thus $\mathrm{R}$ is a division ring. \#

\section{3-The relation between MGP-rings and other rings}

In this section we give further properties of the MGP-rings and link between MGP- rings and other rings .

We shall begin this section with the following result, which gives the connection between MGP-rings and weakly regular rings.

Following [11], a ring $\mathrm{R}$ is a right (left) weakly regular if $\mathrm{I}^{2}=\mathrm{I}$ for each right (left) ideal $I$ of $R$. Equivalently, if $a \in a R a R(a \in R a R a)$ for every a in $\mathrm{R}$. Then $\mathrm{R}$ is called weakly regular.

\section{Theorem 3.1 :}

Let $\mathrm{R}$ be a right MGP-ring and satisfying (*). Then $\mathrm{R}$ is a reduced weakly regular ring .

Proof : Let a be a non zero element in $\mathrm{R}$ with $\mathrm{a}^{2}=0$. Let $\mathrm{M}$ be a maximal right ideal containing $\mathrm{r}$ (a). Since $\mathrm{a} \in \mathrm{r}$ (a) $\subseteq \mathrm{M}$ and $\mathrm{R}$ is an MGP-ring, then there exists $\mathrm{b} \in \mathrm{M}$ and a positive integer $\mathrm{n}$ such that $\mathrm{a}^{\mathrm{n}}=\mathrm{ba}^{\mathrm{n}}$, which implies that $(1-\mathrm{b}) \in \mathrm{l}(\mathrm{an}) \subseteq \mathrm{r}$ (a) $\subset \mathrm{M}$, yielding $1 \in \mathrm{M}$, which is a contradiction .

Therefore, $\mathrm{a}=0$, and hence $\mathrm{R}$ is a reduced ring. We show that $\mathrm{RxR}+\mathrm{r}(\mathrm{x})=\mathrm{R}$, for any $\mathrm{x} \in \mathrm{R}$.

Suppose that there exists $y \in R$ such that $R y R+r(y) \neq R$.

Then there exists a maximal right ideal $M$ of $R$ containing $R y R+r(y)$. Since $\mathrm{R}$ is a right MGP-ring, there exists $\mathrm{a}$ in $\mathrm{M}$ and a positive integer $\mathrm{n}$ such that $\mathrm{y}^{\mathrm{n}}=\mathrm{a} \mathrm{y}^{\mathrm{n}}$ implying that $(1-\mathrm{a}) \in \mathrm{l}\left(\mathrm{y}^{\mathrm{n}}\right) \subseteq \mathrm{r}(\mathrm{y}) \subset \mathrm{M}$, whence $(1-\mathrm{a}) \in \mathrm{M}$ and so $1 \in M$ implies that $M=R$, which is a contradiction.

Therefore, $R x R+r(x)=R$, for any $x \in R$.

Hence $\mathrm{R}$ is a right weakly regular ring. Since $\mathrm{R}$ is reduced, it also can be easily verified that $\mathrm{R}$ is a weakly regular ring. \#

\section{Definition 3.2: [9]}

A ring $\mathrm{R}$ is said to be a right (left) Kasch ring if every maximal right (left) ideal is a right (left) annihilator .

\section{Theorem 3.3 :}


Every semi commutative right MGP-ring is a right Kasch ring .

Proof: Let $M$ be any maximal right ideal of $R$ and let $Y(R)$ be the right singular ideal of $\mathrm{R}$.

If $\mathrm{M} \cap \mathrm{Y}(\mathrm{R})=0$, then for any $\mathrm{y} \in \mathrm{Y}(\mathrm{R}), \quad \mathrm{y} \notin \mathrm{M}$, this implies that $\mathrm{r}(\mathrm{y})$ is an essential right ideal of $\mathrm{R}$.

Let $\mathrm{x} \in \mathrm{r}(\mathrm{y}) \cap \mathrm{r}(1-\mathrm{y})$, then $\mathrm{yx}=0$ and $(1-\mathrm{y}) \mathrm{x}=0$ yields $\mathrm{x}=\mathrm{yx}=0$.

Therefore $\mathrm{r}(\mathrm{yy})=0$. Since $\mathrm{R}$ is semi $-\mathrm{y})=0$, whence $\mathrm{r}(1-\mathrm{r}(\mathrm{I} \cap)$ commutative ring, then we have $1(1-\mathrm{y})=0$.

By Theorem (2.3),(1-y) is an invertible element of R. Hence $\mathrm{y} \in \mathrm{J} \subset \mathrm{M}$, a contradiction.

Thus $\mathrm{M} \cap \mathrm{Y}(\mathrm{R}) 0 \neq$. Let $0 \cap \mathrm{M} \in \mathrm{a} \neq \mathrm{Y}(\mathrm{R})$.

Since $\mathrm{R}$ is an MGP-ring, then there exists $\mathrm{b} \in \mathrm{M}$ and a positive integer $n$ such that $a^{n}=b a^{n}=a r a^{n}$. We claim that $r(a r) \cap a^{n} R=0$.

If not, let $d \in r($ ar $) \cap a^{n} R$. Then ar $d=0$ and $d=a^{n} x$ for some $x \in R$, so $\operatorname{ara}^{\mathrm{n}} \mathrm{x}=0$ implies that $\mathrm{a}^{\mathrm{n}} \mathrm{x}=0=\mathrm{d}$. Therefore, $\mathrm{r}$ (ar) $\cap \mathrm{a}^{\mathrm{n}} \mathrm{R}=0$.But $\mathrm{r}(\mathrm{ar})$ is essential ,then $a^{n} R=0$ and hence $a^{n} x=0$, for all $x \in R$ implies that $a^{n} \in 1(x)=r(x)$. Therefore, $M=r(x)$. Thus $R$ is a right Kasch ring. \#

\section{Corollary 3.4:}

Let $\mathrm{R}$ be a reduced MGP-ring. Then $\mathrm{R}$ is a Kasch ring

Proof: Since R is a reduced right MGP-ring .Then by Theorem (3.3) R is a Kasch ring .\# 


\section{REFERENCES}

[1] Ahmed, J. S. (2003) "On YJ-injectvity", a Ph. D., Thesis University, Mosul.

[2] Al- Ezeh, H. (1989) "Pure ideals in commutative reduced Gelfand rings with unity", Arch .Math., Vol. 53 , Pp.266-269.

[3] Al- Ezeh, H. (1989) "On generalized PF-rings", Math J. Okayama Univ. Vol.31, , Pp.25-29

[4] Al- Ezeh, H. (1996) "Purity of the augmentation ideal of a group ring", Dirasat,Na.and Eng.Sciences.Vol.23,No.2, ,Pp.181-183.

[5] Al- Ezeh, H. (1998) "The pure spectrum of PF-ring", Comm. Math. Univer. S.P. Vol. 37, No. 2, Pp.18-29 .

[6] Fieldhouse, D.J(1969) "Pure theories", Math .Ann. 184, Pp.1-18.

[7] Fieldhouse, D.J. (1971) "Regular modules over semi local rings", Coll, Math.Sco.Janos Bolyai, Pp.193-196.

[8] Mahmood, A.S.(1995) "On $\pi$-regular rings II" ,J.Ed.and Sci.24, Pp 256-261.

[9] Mahmood, R.D.(2000) "On Pure Ideals and Pure Sub modules", Ph. D. thesis Mosul University.

[10] Shuker, N. H.(2004) "On rings whose simple singular modules are GP-injective", Raf. J. Sci. Vol. 15, No. 1, p. 37 - 40.

[11] Yue C. M. R.;(1983), "On quasi-injectivity and Von-Neumann regularity" ,Monatash., Math .95, Pp.25-23. 